\title{
Dynamics of Mask Use as a Prevention Strategy against SARS-CoV-2 in Panama
}

\author{
Hermógenes Fernández-Marín 1,2,*, Gaspar Bruner-Montero ${ }^{3}{ }^{\mathbb{D}}$, Ana Portugal-Loayza ${ }^{4}$, Virginia Miranda 5 , \\ Alcibíades Villareal ${ }^{1,2}{ }^{\mathbb{D}}$, Eduardo Ortega-Barría ${ }^{6}$, Virginia Núñez-Samudio ${ }^{2,7}$, Iván Landires ${ }^{2,7}$ (D), \\ Luis C. Mejía ${ }^{1,2} \mathbb{D}$, Sandra López-Vergès ${ }^{2,8} \mathbb{D}$, William T. Wcislo ${ }^{9}$ and Jagannatha Rao K.S. ${ }^{1,2} \mathbb{D}$
}

Citation: Fernández-Marín, H.; Bruner-Montero, G.; Portugal-Loayza, A.; Miranda, V.; Villareal, A.;

Ortega-Barría, E.; Núñez-Samudio, V.; Landires, I.; Mejía, L.C.;

López-Vergès, S.; et al. Dynamics of Mask Use as a Prevention Strategy against SARS-CoV-2 in Panama. Int. J. Environ. Res. Public Health 2021, 18, 12982. https://doi.org/10.3390/ ijerph182412982

Academic Editor: Paul B. Tchounwou

Received: 21 September 2021

Accepted: 26 October 2021

Published: 9 December 2021

Publisher's Note: MDPI stays neutral with regard to jurisdictional claims in published maps and institutional affiliations.

Copyright: (c) 2021 by the authors. Licensee MDPI, Basel, Switzerland. This article is an open access article distributed under the terms and conditions of the Creative Commons Attribution (CC BY) license (https:// creativecommons.org/licenses/by/ $4.0 /)$
1 Centro de Biodiversidad y Descubrimiento de Drogas, Instituto de Investigaciones Científicas y Servicios de Alta Tecnología (INDICASAT AIP), Clayton 0843-01103, Panama; alcibiadesvillarreal@gmail.com (A.V.); LMejia@indicasat.org.pa (L.C.M.); JRao@indicasat.org.pa (J.R.K.S.)

2 Sistema Nacional de Investigación, Panamá 0816-02582, Panama; virysamudio@yahoo.es (V.N.-S.); ivanlandires@yahoo.es (I.L.); slopez@gorgas.gob.pa (S.L.-V.)

3 Department of Genetics, University of Cambridge, Cambridge CB2 1TN, UK; gbrunerm@gmail.com

4 Gamboa, Clayton 09098, Panama; anabportugal@gmail.com

5 Complejo Hospitalario Arnulfo Arias Madrid, Caja de Seguro Social, Panamá 1393, Panama; vamd21@hotmail.com

6 Secretaria Nacional de Ciencia, Tecnología e Innovación (SENACYT), Panamá 0816-02582, Panama; eortegabarria@senacyt.gob.pa

7 Instituto de Ciencias Médicas, Las Tablas 06001, Panama

8 Gorgas Memorial Institute of Health Studies, Panamá 0816-02593, Panama

9 Smithsonian Tropical Research Institute, Panamá 0843-03092, Panama; WcisloW@si.edu

* Correspondence: HFernandez@indicasat.org.pa

Abstract: Early in the SARS-CoV-2 pandemic, many national public health authorities implemented non-pharmaceutical interventions to mitigate disease outbreaks. Panamá established mandatory mask use two months after its first documented case. Initial compliance was high, but diverse masks were used in public areas. We studied behavioral dynamics of mask use through the first two COVID19 waves in Panama, to improve the implementation of effective, low-cost public health containment measures when populations are exposed to novel air-borne pathogens. Mask use behavior was recorded from pedestrians in four Panamanian populations (August to December 2020). We recorded facial coverings and if used, the type of mask, and gender and estimated age of the wearer. Our results showed that people were highly compliant (>95\%) with mask mandates and demonstrated important population-level behaviors: (1) decreasing use of cloth masks over time, and increasing use of surgical masks; (2) mask use was 3-fold lower in suburban neighborhoods than other public areas and (3) young people were least likely to wear masks. Results help focus on highly effective, low-cost, public health interventions for managing and controlling a pandemic. Considerations of behavioral preferences for different masks, relative to pricing and availability, are essential for optimizing public health policies. Policies to increase the availability of effective masks, and behavioral nudges to increase acceptance, and to facilitate mask usage, during the ongoing SARS-CoV-2 pandemic, and for future pandemics of respiratory pathogens, are key tools, especially for nations lagging in access to expensive vaccines and pharmacological approaches.

Keywords: surgical mask; cloth mask; population response; behavioral modifications; public health

\section{Introduction}

In December 2019, an acute respiratory disease known as Coronavirus disease (COVID19) was detected in the Chinese city of Wuhan, and the causative agent of the outbreak was named severe acute respiratory syndrome coronavirus 2 (SARS-CoV-2). SARS-CoV-2 has affected the public health systems of every country in the world [1], infecting more than 200 million people and causing over 4.3 million deaths since reported in December 
2019 through August 2021. The COVID-19 pandemic has forced world-leading health organizations to provide recommendations on how public health systems should operate generally across the globe [2,3]. A recommendation to minimize the transmission of the virus, for which the main transmission mechanism is via aerosol droplets [4,5], was the use of personal protective equipment (PPE) to protect healthcare workers and infected people. Not surprisingly, many governments adopted these recommendations and further included mask usage for the general population with the integration of other non-pharmacological interventions to prevent the rapid transmission of the virus in the population.

Throughout the first year of the pandemic, the global public health system lacked the pharmacological tools for the prophylactic and therapeutic management of COVID-19. However, the implementation of non-pharmacological public health measures has allowed for the containment, management, and control of the disease to varying degrees. Non-pharmacological measures, such as social distancing, self-isolation (including quarantine), changes in hygienic behavior (e.g., increased frequency of handwashing), and face-coverings in public areas were preventive strategies suggested by international health agencies. Perhaps the use of face masks has been the most controversial strategy of prevention. There are many types of masks and where, when, and how to use them can be complicated to evaluate, and for some individuals, mask use is perceived to impair individual freedom.

Face-covering of the general population was quickly adopted and recommended as one of the most important elements for preventing the spread of COVID-19 [6-8]. The use of a facial mask was recommended because the social distance among persons (more than $1.5 \mathrm{~m}$ ) was difficult to maintain in indoor settings and crowded areas, and particularly given the high prevalence of presymptomatic and non-symptomatic cases. More importantly, the use of a facial mask may reduce the aerosol transmission of the virus from infected and non-symptomatic patients to the healthy population [8]. Furthermore, high public compliance with mask usage is an effective and low-cost collective action that reduces viral transmission at the public and community level $[9,10]$. However, the prevalence of different types of masks on the population and their different levels of protection can affect the impact of the transmission [8].

There is limited information about the prevalence of different types of masks at the population level [8-11]. No study has reported how the usage of different types of masks has changed throughout the COVID-19 pandemic, or previous pandemics [10,11]. Predictive models suggest the appropriate time to implement compulsory mask-wearing is when the first infection is detected, to avoid increasing infection rates [12] since the evidence shows that compulsory mask-wearing results in a greater reduction of COVID-19 growth rates at the community level [13]. Understanding behavioral responses to the received information about mask efficacy as well as to the supply and demand of masks during the pandemic can improve the efficiency of the system, facilitating transport logistics, mitigating the volatility of wholesale prices, and reducing the shortage of supplies between the general population and healthcare workers [14-17]. Here we describe the behavior of mask-wearing during the end of the first wave and the beginning of the second wave of SARS-CoV2 infections in Panama.

\section{Materials and Methods}

\subsection{Data Collection}

Observations of the type of mask used were recorded in urban areas of four provinces of the Republic of Panama, including the Provinces of Panama (Amelia Denis de Icaza in San Miguelito's districts, and Felipillo (Pacora) at Panama's districts), Cocle (city of Penonome), Veraguas (city of Santiago), and Chiriqui (city of David), between 28 August and 12 December 2020. In each locality, data were recorded 4 to 6 days per month. Each day the observations were conducted in each one of the following places from August to December 2020: (i) from 7:00 a.m. to 8:00 a.m. in bus and train terminals, (ii) from 8:30 to 9:30 along public walkways of main avenues, (iii) and from 10:00 to 11:00 a.m. 
in supermarkets. From November to December 2020, additional data were collected in neighborhood areas from 4:00 p.m. to 5:00 p.m. Data were collected by manual counting. At each site, an observer was located from 2 to $5 \mathrm{~m}$ from local foot traffic; observers used a printed Excel table to record data. One individual was observed at a time, and we recorded as many individuals as possible in the observation time per day. These observations were repeated $4-5$ days per month for 5 months in each place and included: (i) biological gender (man or woman), (ii) use of mask (correct or incorrect), (iii) type of mask-wearing (cloth, surgical, KN95, valve, or other types of masks, which included all type of masks that were not aforementioned), (iv) the estimated range of the age (early adulthood $<19$, middle adulthood 20 to $<40$, late-middle adulthood 40 to $<60$, and late adulthood $>60[18,19]$. Masks were classified as follows: cloth masks are any fabric masks with cotton or synthetic cloth; surgical masks are dispensable colored nonmedical masks of 3 layers; KN95 masks are non-medical masks of four or five layers curved design with contour adapted to the face; valved masks are considered any type of masks that used an exhalation valve and the "others" category included any other facial covering, including scarves and kerchiefs. Initial observations in August and September indicated that some people wore masks incorrectly, which was tabulated as missing data. In October, November, and December, we scored mask use as "correct" or not, with the former defined as the mask covering the nose and mouth of the observed person; otherwise, it was tabulated as incorrect use. The price of masks in the market was quoted in Panama Compra (https:/ / www.panamacompra.gob.pa accessed on 14 April 2021) and local commercial shops, such as hardware stores, warehouses, pharmacies, supermarkets, and shopping malls.

\subsection{Data Processing and Analyses}

To evaluate face mask usage (correct or incorrect) in public areas, we used a Generalized Linear Mixed Model (GLMM) with a binomial distribution and logic link function. We used a GLMM because this approach allows more flexible modeling to analyze non-normal data that are hierarchically structured and when there are random effects [20,21]. After removing the missing data from 64,650 observations, the GLMM model was performed with 36,441 observations. The model included the predictor variables gender (male and female), place (main streets, market, neighborhood, and terminal station), and age (early, middle, late middle, and late adulthood), and the interactions between gender $\times$ place, and gender $\times$ age. The region was included as a random effect to account for differences among populations, with the predictor variable place nested within the region. A total of 64,650 observations were documented during the study, and the range of people observed was from 41 to 278 per hour.

We conducted all statistical analyses in R (www.r-project.org) [22]. The GLMMs were generated using the 'glmmTMB( $)$ ' function in the 'glmmTMB' package [23]. The model selection was based on the Akaike Information Criteria comparing all models via the 'AICtab()' function in the 'bbmle' package [24]. To validate our model, a residual diagnostic analysis was performed by simulating 1000 times the model's residuals using the 'simulateResiduals()' function in the DHARMa package [25]. Overdispersion was tested with the 'overdisp_fun()' function and multicollinearity with the 'check_collinearity()' function in the 'performance' package. We used the Wald $\chi^{2}$ tests with a type III sum of squares to estimate the significant effects of our model using the 'Anova()' function in the 'car' package [26], and odds ratios (OR) were subtracted by exponentiating the coefficients of the model.

To determine whether the frequency of use of different types of masks changed over time, we used a multinomial logistic regression model (MLRM), which can help to characterize observations when the response variable has multiple categories. Mask type (cloth, KN95, surgical, valve, and others) was evaluated as a function of gender, place, and time period (continuous predictor variable) in the MLRM using the 'multinom' function in the nnet package [27]. The MLRM was performed with 64,006 observations after removing 
missing data and variable "other masks". Model selection, multicollinearity, and ORs were estimated as mentioned above. All graphs were generated with the function 'ggplot( ()$^{\prime}$ in the 'ggplot2' package [28], and final editions were performed in the program Inkscape (www.inkscape.org, accessed on 20 September 2021).

\section{Results}

To evaluate face mask usage in the population, we analyzed 36,266 observations in different public areas. Among these observations, 34,266 (94\%) people were observed wearing a mask, and $2175(6 \%)$ people were not wearing a mask. Men $(93 \%, n=20,122)$ and women $(95 \%, n=16,319)$ did not differ in the use of mask (GLMM, $\left.\chi^{2}=1.04, p=0.306\right)$. In contrast, face mask use differed at different places (GLMM, $\left.\chi^{2}=29.19, p<0.0001\right)$ : mask use was more prevalent among people at transport terminals $(94 \%, n=15,810)$, main streets $(95.1 \%$, $n=13,894)$, and supermarkets $(98.3 \%, n=4763)$, decreasing to $75 \%(n=1974)$ in neighborhood areas. Additionally, mask use differed with age (GLMM, $\left.\chi^{2}=18.94, p=0.0002\right)$, used more frequently by middle $(93.5 \%, n=19,442)$, late-middle $(95 \%, n=11,673)$, and elderly ages $(95.6 \%, n=3134)$, relative to young adults $(90 \%, n=2192)$.

The odds ratios of people wearing masks between supermarkets, transport terminals stations, and main streets did not differ $(p>0.05)$, but people in sub-urban neighborhood areas were 20 times (OR 0.05 [95\% CI 0.01-0.16], $p<0.0001$, Figure 1) less likely to wear a mask. While the odd ratios of middle, late-middle, and late adulthood groups did not differ in face mask-wearing $(p>0.05)$, people in the early adulthood group are 1.49 times (OR 0.67 [95\% CI 0.54-0.84], $p<0.0001$, Figure 1) less likely to wear a mask. For the interactions, there were no differences in odds between women and men at supermarkets and main streets areas $(p>0.05)$. In contrast, women in neighborhood areas (OR 1.78 [95\% CI 1.34-2.38], $p<0.0001$, Figure 2A) and transport terminals (OR 1.46 [95\% CI 1.18-1.81], $p=0.001$, Figure 2A), respectively, had a 78\% and $56 \%$ increase in the odds of wearing a mask compared to men (Figure 2B). While women in early, late-middle, and late adulthood groups were more likely to wear a mask than men (Figure 2B)

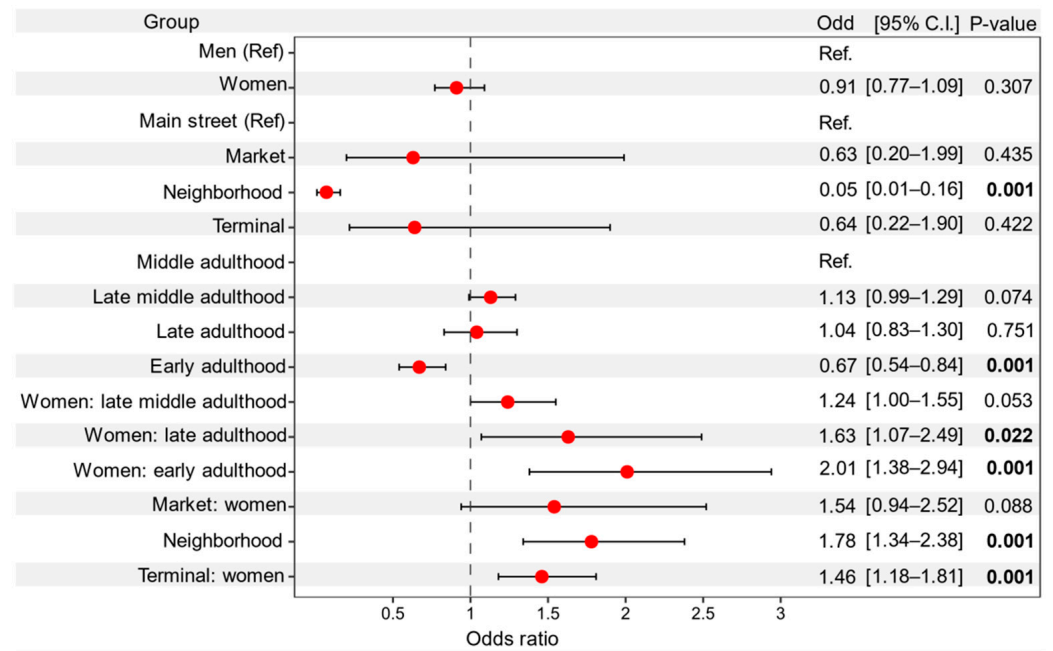

Figure 1. Odds ratios for people wearing a mask during the COVID-19 pandemic. Odds ratios and 95\% confidence intervals for the group terms gender (men and women), place (mean street, market, neighborhood, and terminal), and age (early, middle, late-middle, and late adulthood). We included the interactions gender $\times$ place, and gender $\times$ age using a GLMM with a binomial distribution, accounting for the random effect of region, and place nested within the region. There were 36,441 observations included in the model. P-values denote the statistical significance of the model. Men, main streets, and middle adulthood were used as reference terms within their groups denoted as Ref. The vertical dashed line represents the null value (odds ratio $=1.0$ ). Bold values represent statistical significance at the $p<0.05$ level. 


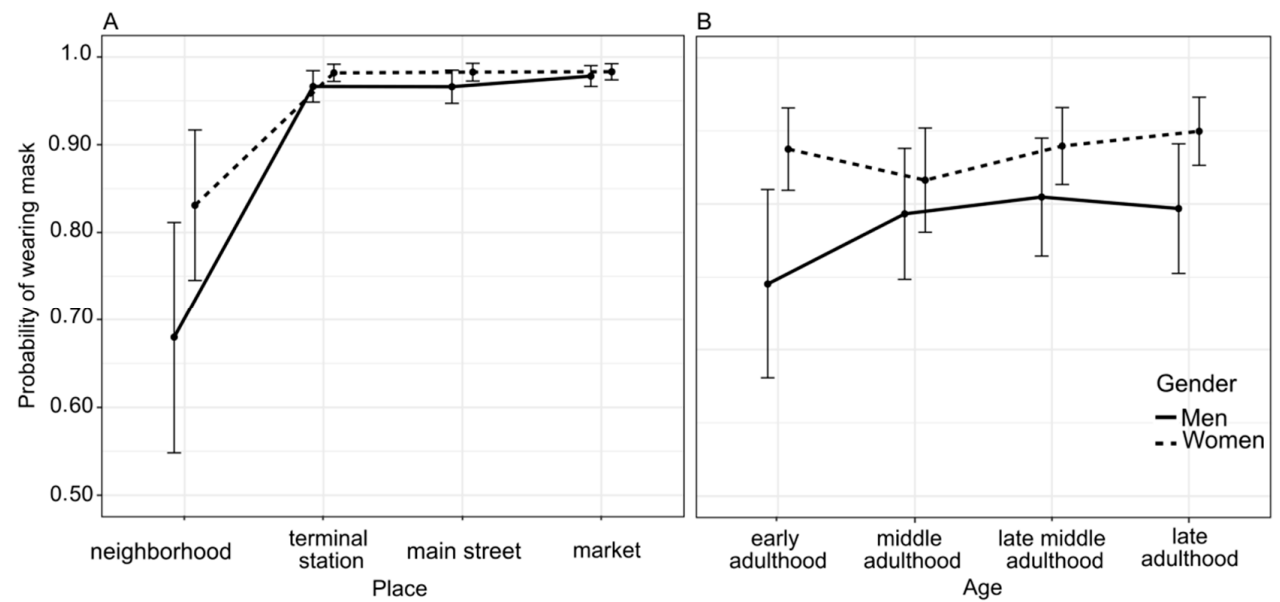

Figure 2. Wearing mask probability during the COVID-19 pandemic. (A) Interaction plot showing the probability of face mask-wearing between genders at different public areas, and (B) the probability of wearing masks between gender at different ages. The probabilities were estimated from a binomial GLMM across observations $(n=36,441)$. Error bars represent the standard error of the mean.

Different types of face mask protection were recorded $(n=64,650)$ from four areas of Panama (Figure 3) during a rapid rise period of the COVID-19 pandemic (Figure 4A). We found substantial differences in the use of difference types of masks in the population, with most people wearing surgical $(68 \%, n=44,184)$ and cloth $(27.2 \%, n=17,627)$ masks, and fewer people wearing KN95 $(2.36 \%, n=1527)$, valve masks $(1.16 \%, n=735)$, and other masks $(0.89 \%, n=577)$. Women were 3.5 times more likely to wear cloth (OR 3.54 [95\% CI 2.96-4.25], $p<0.0001$ ), KN95 (OR 3.61 [95\% CI 2.94-4.44], $p<0.001$ ), and surgical (OR 3.71 [95\% CI 3.10-4.44], $p<0.001$ ) masks than men, relative to people wearing valve masks (Table 1). There was a significant decrease in people wearing cloth masks over time (OR 0.98 [95\% CI 0.96-0.99], $p=0.001$ ), Figure 4B). Conversely, the odds of people wearing surgical masks over time increased $2 \%$ compared to people wearing valve masks (OR 1.02 [95\% CI 1.01-1.04], $p=0.002$ ), Figure 4B). In neighborhood areas, people are 1.98 and 1.83 times more likely to wear cloth (OR 1.98 [95\% CI 1.10-3.58], $p=0.023$, Table 1) and surgical (OR 1.83 [95\% CI 1.02-3.29], $p=0.043$, Table 1) masks than valve masks, respectively. The late adulthood group is 1.53 and 2.17 times more likely of wearing cloth (OR 1.53 [95\% CI 1.02-3.29], $p=0.043$ ) and KN95 (OR 2.17 [95\% CI 1.60-2.94], $p<0.001$ ) masks than valve masks (Table 1 ).

Table 1. Odds ratio based on the multinomial logistic regression model.

\begin{tabular}{llllll}
\hline Response & Predictors & Odds Ratio & 95\% C.I. & Wald-Test & $p$-Value \\
\hline Cloth vs. valve & & & & & \\
& Women & 3.54 & $2.96-4.25$ & 13.69 & $\mathbf{0 . 0 0 1}$ \\
& Time period & 0.98 & $0.96-0.99$ & -3.39 & $\mathbf{0 . 0 0 1}$ \\
& Market & 1.04 & $0.84-1.28$ & 0.35 & 0.723 \\
& neighborhood & 1.98 & $1.10-3.58$ & 2.27 & $\mathbf{0 . 0 2 3}$ \\
& Terminal & 1.1 & $0.93-1.31$ & 1.14 & 0.253 \\
& Early adulthood & 1.24 & $0.85-1.82$ & 1.12 & 0.263 \\
KN95 vs. valve & Late middle adulthood & 1.01 & $0.86-1.18$ & 0.09 & 0.931 \\
& Late adulthood & 1.53 & $1.17-2.01$ & 3.06 & $\mathbf{0 . 0 0 2}$ \\
& & & & \\
& Women & 3.61 & $2.94-4.44$ & 12.25 & $\mathbf{0 . 0 0 1}$ \\
& Time period & 1.02 & $1.00-1.03$ & 1.9 & 0.057 \\
& Market & 1.07 & $0.84-1.37$ & 0.56 & 0.578 \\
& neighborhood & 1.17 & $0.57-2.37$ & 0.42 & 0.672 \\
& Terminal & 0.9 & $0.74-1.10$ & -1.01 & 0.312 \\
& Early adulthood & 0.46 & $0.27-0.79$ & -2.82 & $\mathbf{0 . 0 0 5}$ \\
& Late middle adulthood & 1.12 & $0.93-1.36$ & 1.17 & 0.242 \\
& Late adulthood & 2.17 & $1.60-2.94$ & 4.96 & $\mathbf{0 . 0 0 1}$ \\
\hline
\end{tabular}


Table 1. Cont.

\begin{tabular}{llllll}
\hline Response & Predictors & Odds Ratio & 95\% C.I. & Wald-Test & $p$-Value \\
\hline Surgical vs. valve & & & & & \\
& Women & 3.71 & $3.10-4.44$ & $\mathbf{0 . 0 0 1}$ \\
& Time period & 1.02 & $1.01-1.04$ & 3.15 & $\mathbf{0 . 0 0 2}$ \\
& Market & 0.96 & $0.78-1.18$ & -0.4 & 0.69 \\
& neighborhood & 1.83 & $1.02-3.29$ & 2.02 & 0.043 \\
& Terminal & 1.02 & $0.86-1.21$ & 0.24 & 0.813 \\
& Early adulthood & 0.95 & $0.65-1.38$ & -0.29 & 0.773 \\
& Late middle adulthood & 0.8 & $0.69-0.94$ & -2.71 & $\mathbf{0 . 0 0 7}$ \\
& Late adulthood & 1.19 & $0.91-1.56$ & 1.27 & 0.204 \\
\hline
\end{tabular}

Analysis was performed using a multinomial logistic regression model. The model included the response variable mask type (cloth, $\mathrm{KN} 95$, surgical, and valve) as a function of gender, place, and time period (continuous predictor variable). Bold values represent statistical significance at the $p<0.05$ level.

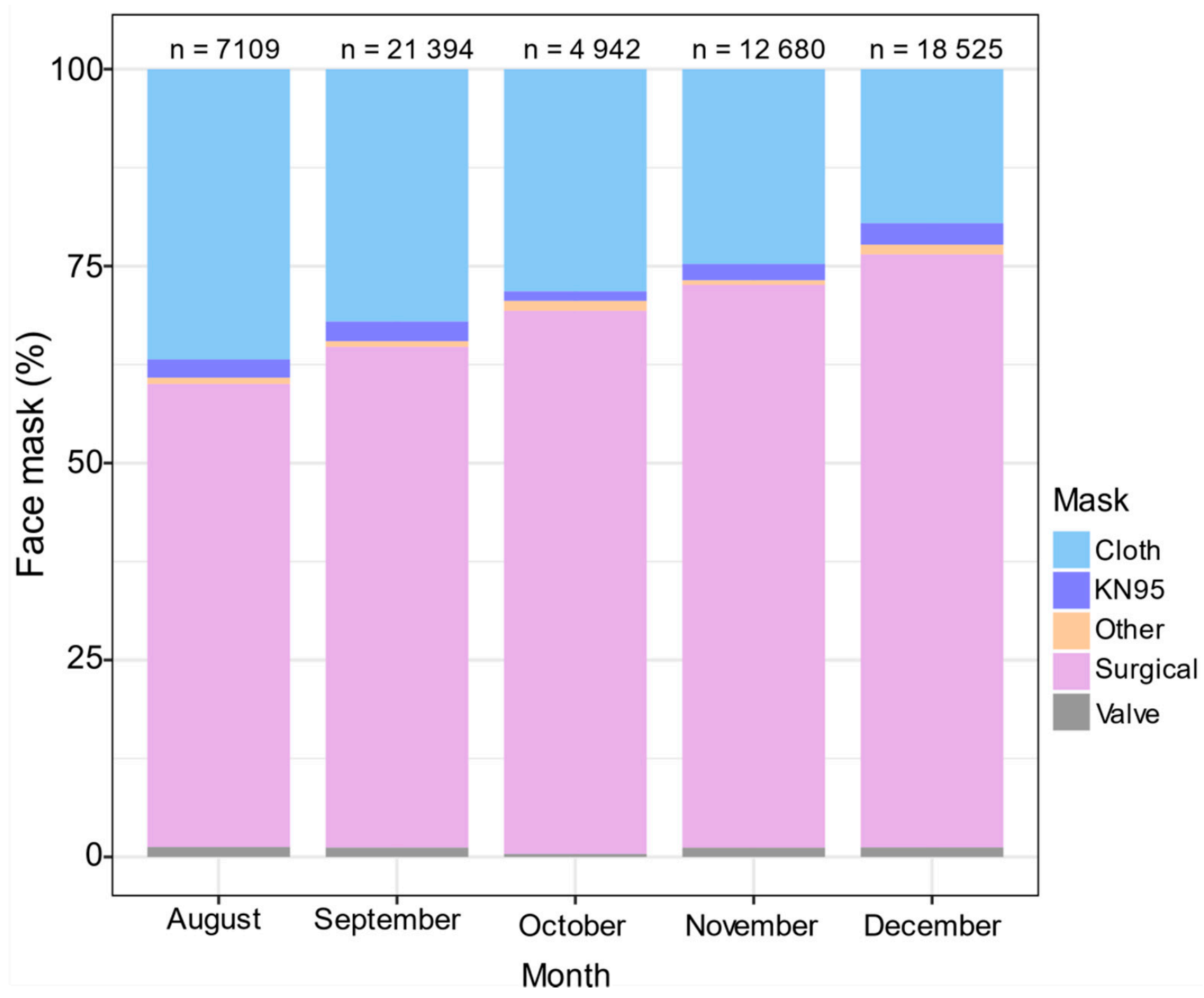

Figure 3. Usages of different types of face mask protection during the COVID-19 pandemic. Percentage of people wearing different types of masks in public areas between August and December 2020. A total of 64,650 observations were documented. 

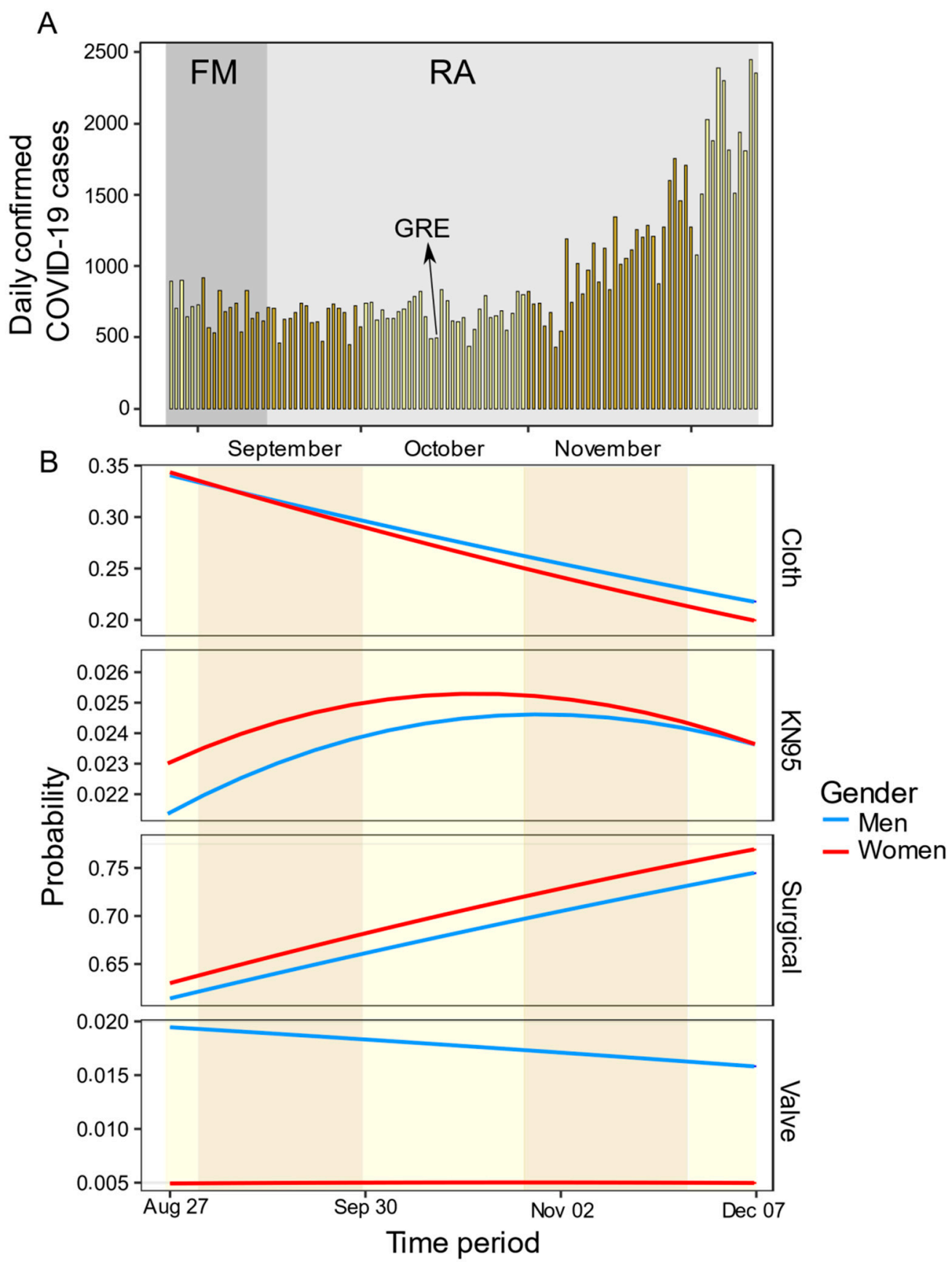

Figure 4. Different types of face mask protection over time during the COVID-19 pandemic. (A) Daily confirmed cases in Panama as a function of time across the observational study. (B) Multinomial logistic regression showing the predicted probability associated with the frequency of use for different types of face masks (cloth, KN95, surgical, and valve) in public areas over time. The model was performed with 64,006 observations, the categorical variable "other" was omitted from the model. A strict gender-based quarantine was mandated by the Panamanian government from 1 April 2020 to February 2021, was lifted at different moments depending of the province and Rt. A relaxation of this policy with the flexibility of movement (FM) in leaving homes is denoted by dark grey, and the reopening of economic activities is in light grey (RA); the arrow indicates the end of gender-based restrictions (GRE).

\section{Discussion}

Panama is a developing country with a high income per capita, but with strong socioeconomic inequality such that a high percentage of the population lives below the poverty 
line [29]. The nation is a worldwide logistical and regional transportation hub, where more than 18 million people transit annually [30]. Socioeconomic characteristics are not fundamentally different from many countries of the Latin American region. As pharmacological approaches are lagging in the region, due to global inequities in vaccine availability $[10,11]$, encouraging hygienic prophylactic behavior, mask usage and social distancing are key strategies to manage the COVID-19 pandemic. Panama reported its first positive cases of COVID-19 in early March 2020, and rapid community transmission was documented with a great diversity of strains [31]. Severe containment and mobility-restriction measures were quickly implemented by the national government [31], reducing labor activity by over $70 \%$, with mandatory use of masks, enforced with fines. The prevalence and dynamics of mask use in Panama observed between August and December 2020, after the first and during the second epidemiological waves of SARS-CoV-2 positive cases, provide insights into the challenges faced and should facilitate preparedness for future pandemics.

The rapid spread of the COVID-19 pathogen created a huge demand worldwide for a limited supply of personal protective equipment (both for the general public and health care systems) and hospital equipment (respirators). The use of face masks during the first and second epidemiological SARS-CoV-2 waves in Panama showed a change in the behavior of the population in the use of types of masks. From August to December 2020, the use of surgical masks increased from $58 \%$ to $79 \%$, while the use of cloth masks was reduced from $37 \%$ to $19 \%$, while no changes were observed to the use of KN95 and valved masks in this period, both types of masks used by less than $3 \%$ of the people analyzed in this study. During the same period of time, a continuous decrease in the prices of non-medical surgical and KN95 masks was observed, whereas the price of cloth masks decreased only in December 2020 (Table 2). Two non-competitive hypotheses can explain this change in strategy at the population level. The first hypothesis is the change in the purchasing power of people. Our data were taken in bus and subway terminals, and in main avenues in the different cities, which suggests that people with low and medium purchasing power were observed so that work suspension could influence mask use at the population level. While a gradual economic recovery could change people's purchasing power, enabling them to acquire surgical masks. Additionally, at the beginning of the pandemic, cloth masks became part of fashion culture, and producing them became a means of financial support for family businesses, but later information in the media and from public health authorities about the relative inefficiency of cloth masks, may have induced a decrease of their use as soon as people have learned that cloth masks did not offer them the best protection to prevent the spread of SARS-CoV-2 relative to surgical masks [10,11]. Surgical and KN95 particulate masks better protect from transmission by aerosols and large particles than fabric masks, but cloth masks protect better than no masks or improper use of them [11]. However, it is possible that the knowledge about the protection efficacy conferred by the type of masks used was not reflected in an increased proportion of use of KN95 masks in the population, possibly because even with a decrease of its price, it remained 15 times more expensive than surgical masks. Subjectively, people report impressions that it was more difficult to breathe when using KN95 or N95 masks than surgical masks in the hot and humid weather in the tropics [32].

In general, women are more proactive in employing preventative health practices [33], as observed in preventive behavior against coronavirus infection [34]. This observation is supported by our data, where a high proportion of women wore masks than men. Our data were based on similar proportions of observations from women and men $(51.5 \%$ men and $48.5 \%$ women). However, Panama applied a mandatory gender-based restriction on activity that overlapped with times of our data collection from August to October, but this restriction did not apply to labor activities. Women were observed to wear masks in higher proportion to men. Our data showed a clear pattern that younger people, independent of gender, were wearing masks less frequently than older persons. Similarly, observations from the USA showed that younger men wore masks at a lower frequency than older men and women [35]. 
Table 2. Information about prices per unit of cloth, surgical and KN95 non-medical face masks selling in Panama from August to December 2020.

\begin{tabular}{cccc}
\hline $\begin{array}{c}\text { Month } \\
(\mathbf{2 0 2 0 )}\end{array}$ & $\begin{array}{c}\text { Prices per Unit of } \\
\text { Surgical Masks } \\
\text { Mean } \pm \text { SD }\end{array}$ & $\begin{array}{c}\text { Prices Range per } \\
\text { Unit of Cloth Masks }\end{array}$ & $\begin{array}{c}\text { Prices per Unit of } \\
\text { KN 95 Masks } \\
\text { Mean } \pm \text { SD }\end{array}$ \\
\hline $\begin{array}{c}\text { August } \\
\text { September }\end{array}$ & $0.19 \pm 0.08$ & $1.50-3.50$ & $1.86 \pm 0.95$ \\
October & $0.08 \pm 0.04$ & $1.50-3.50$ & $1.65 \pm 0.97$ \\
November & $0.09 \pm 0.04$ & $1.50-3.50$ & $1.82 \pm 0.91$ \\
December & $0.07 \pm 0.05$ & $1.50-3.50$ & $1.12 \pm 0.28$ \\
\hline
\end{tabular}

Face mask prices in US\$ per unit (mean \pm SD) or range. Prices were obtained from Panama Compra website (https://www.panamacompra.gob.pa/Inicio/\#!// accessed on 14 April 2021), and information from Instagram accounts of established commercial outlets.

\section{Conclusions}

Of relevance for public health strategies in reducing the contagion rate, is to identify elements in the behavior of the population that may shape dynamics of disease transmission, and then create policies around them to achieve public health objectives. Our study identified that people under the estimated age of 20, and at the neighborhood level, used masks less frequently. Patterns of mask use were similar among different sites in Panama, with lower compliance among the youth, which will be the last age group to be vaccinated and should be targets of outreach and education, as they can be spreaders during the epidemic, especially with the origin and spread of new variants of SARS-CoV-2 like the Delta variant, with a higher risk to develop severe symptoms than at the beginning of the epidemic with the wild type virus. Scientific communication is crucial to keeping the population updated about the efficiency of the different strategies of prevention and the importance of protecting themselves, but also the role they could play in viral transmission and thus, the responsibility each person has in protecting others. Public health programs to make masks widely available, and mandate their use, represent highly effective, cost-efficient, solutions to decrease the spread of airborne infectious diseases.

Author Contributions: Conceptualization: H.F.-M., A.P.-L., V.M.; Study design and Methodology: H.F.-M., A.P.-L.; Literature search: H.F.-M., J.R.K.S., S.L.-V., W.T.W.; Data collection: H.F.-M.; Data analyses: G.B.-M., H.F.-M.; Data interpretation: H.F.-M., A.P.-L., V.M., G.B.-M., A.V., L.C.M., S.L.-V., W.T.W.; Writing (first draft): H.F.-M., G.B.-M., A.P.-L., V.M., A.V., E.O.-B., V.N.-S., I.L., L.C.M., S.L.-V., W.T.W., J.R.K.S.; Writing (Review and Editing): S.L.-V., W.T.W.; Funding acquisition: H.F.-M. All authors have read and agreed to the published version of the manuscript.

Funding: This research was funded by Grant 11-2020 SNI, Senacyt, Panama.

Institutional Review Board Statement: The study was recorded by the Ministry of Health and an exemption review approved by Comité Nacional de Bioética de la Investigación CNBI 109,2021, Panamá.

Informed Consent Statement: Not applicable.

Data Availability Statement: Fernandez-Marin, Hermogenes (2021), “Dynamics of mask use as a prevention strategy against SARS-CoV-2 in Panama", Mendeley Data, V1, doi: 10.17632/92wp53s8sn.1.

Acknowledgments: We are grateful to Anna Melhado for helping to collect some information on prices of masks. The Sistema Nacional de Investigación of the Republic of Panama granted funds to conduct the study.

Conflicts of Interest: The authors declare no conflict of interest.

\section{References}

1. Reid, M.; Abdool-Karim, Q.; Geng, E.; Goosby, E. How will COVID-19 transform global health post-pandemic? Defining research and investment opportunities and priorities. PLoS Med. 2021, 18, e1003564. [CrossRef]

2. Gostin, L.O.; Moon, S.; Meier, B.M. Reimagining global health governance in the age of COVID-19. Am. J. Public Health 2020, 110, 1615-1619. [CrossRef] 
3. World Health Organization. Coronavirus Disease 2019 (COVID-19) Situation Report-71. Available online: https:/ /www.who. int/docs / default-source/coronaviruse/situation-reports /20200331-sitrep-71-covid-19.pdf?sfvrsn=4360e92b_8 (accessed on 31 March 2020).

4. Liu, Y.; Ning, Z.; Chen, Y.; Guo, M.; Liu, Y.; Gali, N.K.; Sun, L.; Duan, Y.; Cai, J.; Westerdahl, D.; et al. Aerodynamic analysis of SARS-CoV-2 in two Wuhan hospitals. Nature 2020, 582, 557-560. [CrossRef]

5. Zhang, X.; Ji, Z.; Yue, Y.; Liu, H.; Wang, J. Infection risk assessment of COVID-19 through aerosol transmission: A case study of South China seafood market. Environ. Sci. Technol. 2021, 55, 4123-4133. [CrossRef]

6. Feng, S.; Shen, C.; Xia, N.; Song, W.; Fan, M.; Cowling, B.J. Rational use of face masks in the COVID-19 pandemic. Lancet Respir. Med. 2020, 8, 434-436. [CrossRef]

7. National Health Service (UK). Are Face Masks Useful for Preventing Coronavirus? 2020. Available online: https://www.nhs.uk/ conditions / coronavirus-covid-19/common-questions / (accessed on 9 April 2020).

8. Greenhalgh, T.; Schmid, M.B.; Czypionka, T.; Bassler, D.; Gruer, L. Face masks for the public during the covid-19 crisis. BMJ 2020, 369, m1435. [CrossRef] [PubMed]

9. Chu, D.; Akl, E.; Duda, S.; Solo, K.; Yaacoub, S.; Schunemann, H. Physical distancing, face masks, and eye protection to prevent person-to-person transmission of SARS-CoV-2 and COVID-19: A systematic review and meta-analysis. Lancet 2020, 395, 1973-1987. [CrossRef]

10. Howard, J.; Huang, A.; Li, Z.; Tufekci, Z.; Zdimal, V.; van der Westhuizen, H.M.; von Delft, A.; Price, A.; Fridman, L.; Tang, L.H.; et al. An evidence review of face masks against COVID-19. Proc. Nat. Acad. Sci. USA 2021, 118, e2014564118. [CrossRef]

11. Cheng, Y.; Ma, N.; Witt, C.; Rapp, S.; Wild, P.S.; Andreae, M.O.; Pöschl, U.; Su, H. Face masks effectively limit the probability of SARS-CoV-2 transmission. Science 2021, 372, 1439-1443. [CrossRef]

12. Tay, B.K.; Roby, C.A.; Wu, J.W.; Tam, D.Y. Dynamical analysis of universal masking on the pandemic. Int. J. Environ. Res. Public Health 2021, 18, 9027. [CrossRef] [PubMed]

13. Lyu, W.; Wehby, G.L. Community use of face masks and COVID-19: Evidence from a natural experiment of state mandates in the US. Health Aff. 2020, 39, 1419-1425. [CrossRef]

14. Worby, C.J.; Chang, H.H. Face mask use in the general population and optimal resource allocation during the COVID-19 pandemic. Nat. Commun. 2020, 11, 4049. [CrossRef] [PubMed]

15. Wu, H.L.; Huang, J.; Zhang, C.J.P.; He, Z.; Ming, W.K. Facemask shortage and the novel coronavirus disease (COVID-19) outbreak: Reflections on public health measures. EClin. Med. 2020, 21, 100329.

16. Dallas, M.P.; Horner, R.; Li, L. The mutual constraints of states and global value chains during COVID-19: The case of personal protective equipment. World Dev. 2021, 139, 105324. [CrossRef] [PubMed]

17. Mahmood, S.U.; Crimbly, F.; Khan, S.; Choudry, E.; Mehwish, S. Strategies for rational use of personal protective equipment (PPE) among healthcare providers during the COVID-19 crisis. Cureus 2020, 12, e8248. [CrossRef] [PubMed]

18. Borkan, G.A.; Bachman, S.S.; Norris, A.H. Comparison of visually estimated age with physiologically predicted age as indicators of rates of aging. Soc. Sci. Med. 1982, 16, 197-204. [CrossRef]

19. Olde Rikkert, M.G. Visual estimation of biological age of elderly subjects: Good interrater agreement. Gerontology 1999, 45, 165-167. [CrossRef]

20. Bolker, B.M.; Brooks, M.E.; Clark, C.J.; Geange, S.W.; Poulsen, J.R.; Stevens, M.H.H.; White, J.-S.S. Generalized linear mixed models: A practical guide for ecology and evolution. Trends Ecol. Evol. 2009, 24, 127-135. [CrossRef]

21. Zuur, A.F.; Ieno, E.N.; Elphick, C.S. A protocol for data exploration to avoid common statistical problems. Methods Ecol. Evol. 2010, 1, 3-14. [CrossRef]

22. R Development Core Team. R: A Language and Environment for Statistical Computing; R Foundation for Statistical Computing: Vienna, Austria, 2013.

23. Brooks, M.E.; Kristensen, K.; van Benthem, K.J.; Magnusson, A.; Berg, C.W.; Nielsen, A.; Skaug, H.J.; Mächler, M.; Bolker, B.M. glmmTMB balances speed and flexibility among packages for zero-inflated generalized linear mixed modeling. $R \mathrm{~J}$. 2017, 9 , 378-400. [CrossRef]

24. Bolker, B. Maximum Likelihood Estimation and Analysis with the Bbmle Package. 2014. Available online: https://cran.r-project. org/web/packages/bbmle/vignettes/mle2.pdf (accessed on 20 August 2021).

25. Hartig, F. DHARMa: Residual Diagnostics for Hierarchical (Multi-Level/Mixed) Regression Models. R Package Version 0.1.5. 2017. Available online: http:/ / cran.nexr.com/web/packages/DHARMa/vignettes/DHARMa.html (accessed on 14 May 2021).

26. Fox, J.; Weisberg, S. An R Companion to Applied Regression; Sage publications: Thousand Oaks, CA, USA, 2018.

27. Venables, W.N.; Ripley, B.D. Modern Applied Statistics with S; Springer: New York, NY, USA, 2002.

28. Wickham, H. ggplot2: Elegant Graphics for Data Analysis; Springer: New York, NY, USA, 2016.

29. The World Bank. Data, Panama. 2021. Available online: https://data.worldbank.org/country/PA (accessed on 1 August 2021).

30. Logistics in Panama. Available online: https://www.rvo.nl/sites/default/files/2018/08/Logistics\%20report \%20Panama\%2020 18.pdf (accessed on 1 September 2021).

31. Franco, D.; Gonzalez, C.; Abrego, L.E.; Carrera, J.P.; Diaz, Y.; Caicedo, Y.; Moreno, A.; Chavarria, O.; Gondola, J.; Castillo, M.; et al. Gorgas COVID19 team and Panama COVID19 Laboratory Network. Early transmission dynamics, spread, and genomic characterization of SARS-CoV-2 in Panama. Emerg. Infect. Dis. 2021, 27, 612-615. [CrossRef] 
32. Scarano, A.; Inchingolo, F.; Lorusso, F. Facial skin temperature and discomfort when wearing protective face masks: Thermal infrared imaging evaluation and hands moving the mask. Int. J. Environ. Res. Public Health 2020, 17, 4624. [CrossRef] [PubMed]

33. Umberson, D. Gender, marital status and the social control of health behavior. Soc. Sci. Med. 1992, 34, 907-917. [CrossRef]

34. Olcaysoy Okten, I.; Gollwitzer, A.; Oettingen, G. Gender differences in preventing the spread of coronavirus. Behav. Sci. Policy 2020, 6, 109-122. [CrossRef]

35. Hutchins, H.J.; Wolff, B.; Leeb, R.; Ko, J.Y.; Odom, E.; Willey, J.; Friedman, A.; Bitsko, R.H. COVID-19 Mitigation behaviors by age group-United States, April-June 2020. MMWR Morb. Mortal. Wkly. Rep. 2020, 69, 1584-1590. [CrossRef] 